\title{
Team cognition model based on mutual beliefs and mental subgrouping
}

\author{
Dipta Mahardhika ${ }^{1 *} \mathbb{D}$, Taro Kanno ${ }^{1}$ and Kazuo Furuta ${ }^{2}$
}

\begin{abstract}
In this research, an extension of a dyadic (pair) team cognition model is proposed to describe the cognition of a team with more than two persons. This model provides a comprehensive framework for analysing the cognitive aspects of team interactions, such as team situation awareness, team memory, and human-agent interactions. One important aspect discussed in this research is a process called mental subgrouping. In a team with more than two persons, for each member to think of the other members as a single entity instead of several different individuals is natural. This behaviour is defined as mental subgrouping. By incorporating mental subgrouping into the mutual belief model, this research attempts to more accurately describe the cognition of a team from the perspective of both an outsider and the individual team members.
\end{abstract}

Keywords: Mutual belief, Mental subgrouping, Team cognition

\section{Introduction}

In the last decade, certain notions of the team cognitive construct have been introduced to better understand teamwork and to improve team performance. Some of these notions include the team mental model, transactive memory, group learning, shared situation awareness, and strategic consensus. The team mental model is an organized mental representation of the elements of teamwork that are shared among team members [1]. Transactive memory focuses on knowing who knows what within a team [2]. Group learning, as reviewed by Wilson, Goodman, and Cronin [3], is the sharing, storage, and retrieval process of certain knowledge within a team. Shared situation awareness is a concept that describes the sharedness of the meaning and the projected status of environmental events [4]. Strategic consensus is defined as a shared understanding of strategic priorities. This concept is typically used among managers of companies [5].

In their review, Mohammed, Ferzandi, and Hamilton [6] showed that although all of these notions reference the sharedness of cognition among members, the focus, conceptualization, and methodology are different. They argued that the team mental model (TMM) is broader

\footnotetext{
*Correspondence: dipta@cse.t.u-tokyo.ac.jp

${ }^{1}$ Department of Systems Innovation, Graduate School of Engineering, the

University of Tokyo, 7-3-1 Hongo Bunkyo-ku, Tokyo 113-8656, Japan

Full list of author information is available at the end of the article
}

than other team cognitive constructs. TMM incorporates both task work and teamwork, whereas the others only focus on one of these two constructs. The team mental model can be considered a team-level equivalent to the human cognition model by Endsley [7], which showed three aspects of individual cognition: perception, comprehension, and projection. TMM also fulfils similar functions, i.e., description, explanation, and prediction. Description is the aspect through which a team describes what is happening. Explanation is the aspect through which a team explains why it is happening. Prediction is the aspect through which a team can predict what will happen next given the current situation [8]. The core concept of TMM is that team members have a common view of these three aspects. This overlapping sharedness allows a team to adapt to task demands and enables enhanced decision making and better performance [9]. However, the concept of overlapping sharedness is not enough to explain the cognitive process from the perspective of the members as opposed to the perspective of an outsider. In all cognitive constructs previously mentioned, the emphasis of sharedness is either overlapping, distributed, or both. A pitfall of this categorization is that none of the categories can explain the situation in which a member believes that cognition is shared when it is actually not shared. To add the
照 Springer

(c) 2016 Mahardhika et al. Open Access This article is distributed under the terms of the Creative Commons Attribution 4.0 International License (http://creativecommons.org/licenses/by/4.0/), which permits unrestricted use, distribution, and reproduction in any medium, provided you give appropriate credit to the original author(s) and the source, provide a link to the Creative Commons license, and indicate if changes were made. 
concepts of 'belief of sharedness' in addition to 'sharing as overlapping' and 'sharing as distributed' is important.

Kanno, Furuta, and Kitahara [10] introduced the concept of 'belief of sharedness' through their three-layer model of team cognition. In the model, they do not focus on specific content such as team knowledge or task knowledge. Instead, they emphasize the concept of mutual belief, or the degree of belief about their partners' cognition, in addition to their own cognition and their partners' cognition. This addition is an important concept in defining a team cognitive construct.

The structure of this article is as follows. In the next section, we discuss in greater detail the team cognition model proposed by Kanno, Furuta, and Kitahara [10], including its contribution and limitations. This discussion is followed by an explanation of the newly proposed team cognition model as an extension from the previous model. Next, an experiment was done to explore this phenomenon in a laboratory setting discussion, and the result is discussed. Finally, several theoretical hypotheses based on the model and experiment are proposed.

\section{Previous model \\ Model description}

When people interact with one another, from each individual's perspective, they are not actually exchanging their mental constructs but are, instead, creating a belief about or making inferences about the status of teammates' minds from limited available information. Such a belief can be obtained by receiving information from the outside world (environment) using their senses or through an internal process such as memory recall or reasoning, or a creative process. Humans have the capacity to infer various types of cognitive status of others [11]. Davis [12] mentioned that several ways exist to infer another person's cognitive status (including emotion, thoughts, motives, and intentions), such as mimicry, associative processes, projection, logical inference, mental simulation, and imagination.

Kanno, Furuta, and Kitahara [10] proposed a formal model of team cognition on the basis of the mutual belief concept. The mutual belief condition occurs when members believe that they are sharing the same belief. This condition is necessary for a group to perform a collective action [13].

They described the team cognition within a dyadic group as a three-layer model. The first layer represents individual self-cognition, excluding beliefs about the partner's cognition. The second layer represents one's beliefs about the partner's cognition, and the third layer represents one's beliefs about the partner's belief about one's cognition. This model can be easily understood from the following description of complete team situation awareness. From the perspective of each member, a team has complete awareness of situation $\mathrm{X}$ if and only if each member is aware of $\mathrm{X}$ (status of the first layer), each member believes that his/her partner is also aware of $\mathrm{X}$ (status of the second layer), and each member believes that his/her partner believes that he/she is aware of X (status of the third layer). Theoretically, this concept is ad infinitum; in other words, it can extend to the fourth layer, the fifth layer, and so on. However, three layers are adequate for explaining most of the interaction phenomena in a dyadic group. The term 'aware' refers to the definition by Endsley [7] of situation awareness, or the condition in which one has perceived, comprehended, and projected the future state of an element in the environment - in this example, situation X.

\section{Contribution to team modelling}

One breakthrough made by this three-layer model is the ability to explain various perspectives of 'sharedness'. In the conventional definition, sharedness of cognition is the degree of either overlapped or distributed cognition among members. However, given this three-layer model, sharedness should also consider what members believe about whether or not the cognition is shared (see also [14]). Using that concept, eight perspectives of sharedness can also be defined by incorporating the topological space of mental constructs. These perspectives provide a formal distinction between, for example, a team cognition against a shared cognition, the soundness of a belief against the completeness of a belief, and so on. Some examples are provided in Table 1. This model has been used in several studies, including as a cognitive model for air traffic control [15], perception gap modelling [16], and human interaction modelling [14].

To understand the complexity of a team's cognition, Chant and Ernst [17] and Tuomela [18] suggested that we could use a reductivism point of view. From this perspective, team cognition should be viewed as a set of individual cognitions and a particular relationship. This three-layer model can be one alternative to defining this particular relationship. Practically, having such a definition can help researchers create support systems for a team, such as decision support systems, discussion support systems, and others.

\section{Limitations}

Scalability One limitation of the model is that it was developed on the assumption of a dyadic group.

Table 1 Definitions of sharedness between agents A \& B based on [10]

\begin{tabular}{lll}
\hline Meaning & Topological definition & Note \\
\hline Actual shared cognition & $\mathrm{Ma} \wedge \mathrm{Mb}$ & $\mathrm{Ma}=\mathrm{A}^{\prime} s 1^{\text {st }}$ layer \\
Actual team cognition & $\mathrm{Ma}{ }^{\wedge} \mathrm{Mb}$ & $\mathrm{Mb}=\mathrm{B}^{\prime} \mathrm{s} 1^{\text {st }}$ layer \\
Soundness of A's belief & $\left(\mathrm{Ma}{ }^{\wedge} \mathrm{Mb}^{\prime}\right) / \mathrm{Mb}^{\prime} \mathrm{s} 2^{\text {nd }}$ layer \\
Completeness of A's belief & $\left(\mathrm{Ma}^{\wedge} \mathrm{Mb}^{\prime}\right) / \mathrm{Ma}$ & \\
\hline
\end{tabular}


Therefore, some limitations exist in applying the model to a group larger than two persons. When we attempt to understand how a larger team is mentally modelled in a member's mind, some belief structures cannot be explained by the model.

In the model, only the two perspectives of I and You (singular) can be taken into account, such as "What $I$ think' or 'What $I$ believe you think'. In a larger team, other perspectives should be taken into account, such as he/she, as in 'What I believe you believe about his cognition'.

Mental subgrouping The model by Kanno, Furuta, and Kitahara [10] did not explain another important aspect of a team's cognition. When working on a large team, in addition to thinking individually about other members' cognition (such as, 'What is his intention'), humans also think about their partners' cognition as that of a set of people instead of individuals (such as, 'What is their intention'). For the purpose of this research, we define such behaviour as 'mental subgrouping', which is 'a mental action in an individual's mind of treating several persons as a single entity'.

\section{Method}

\section{New model}

\section{Model description}

In the proposed model, team cognition is described as a set of three layers of mental process and construct, interaction between the layers, and mental subgrouping. The layers are formalized respectively as M, M,' and M". If the partners are more than one person, the second and third layers contain more than one block of mental processes and constructs of each partner. The blocks are represented as each instance of $M, M$, and $M$ ". For a group $\mathrm{G}$ consisting of $\mathrm{n}$ members $\left(\mathrm{Q}_{1}, \mathrm{Q}_{2}, \ldots, \mathrm{Q}_{\mathrm{n}}\right)$, in the mind of each individual member $\left(Q_{i}\right.$ for $\left.0<i \leq n\right)$, cognition and belief are generally defined as follows:

- $\mathrm{M}\left(\mathrm{Q}_{\mathrm{i}}\right)=\mathrm{Q}_{\mathrm{i}}{ }^{\prime}$ s cognition (self-cognition excluding belief about other partner's cognition/belief);

- $\mathrm{M}^{\prime}\left(\mathrm{Q}_{\mathrm{i}}, \mathrm{Q}_{\mathrm{j}}\right)=\mathrm{Q}_{\mathrm{i}}$ 's belief about $\mathrm{M}\left(\mathrm{Q}_{\mathrm{j}}\right)$ (belief about another member's cognition), for $i \neq j, 0<j \leq n$; and

- $\mathrm{M}^{\prime \prime}\left(\mathrm{Q}_{\mathrm{i}}, \mathrm{Q}_{\mathrm{j}}, \mathrm{Q}_{\mathrm{k}}\right)=\mathrm{Q}_{\mathrm{i}}$ 's belief about $\mathrm{M}^{\prime}\left(\mathrm{Q}_{\mathrm{j}}, \mathrm{Q}_{\mathrm{k}}\right)$, (belief about the belief of another member's cognition), for $i \neq j, j \neq k, 0<j \leq n, 0<k \leq n$.

A schematic of the model is shown in Fig. 1.

In Fig. 1, the first layer - the self-cognition layer contains A's own cognition, excluding beliefs about the other partner's cognition M(A). This cognition can include A's situation awareness, intention, emotion, perception, and others.
The second layer - the direct belief layer - contains A's belief about his/her partner's cognition ( $\mathrm{M}^{\prime}(\mathrm{A}, \mathrm{B})$ and $\mathrm{M}^{\prime}(\mathrm{A}, \mathrm{C})$ ). This layer is divided into smaller blocks. Each block contains A's belief about each partner's cognition, which does not include a belief about the partner's belief. This cognition may include what A believes about B's and C's perceptions, thoughts, emotions, intentions, and others. In this case, we assume a group of three persons, giving A two partners and, hence, two blocks in the direct belief layer. The number of blocks is always $n-1$, where $\mathrm{n}$ is the group size.

The third layer is called the projected belief layer. This layer consists of several blocks, explained as follows. Two blocks ( $\mathrm{n}-1)$ exist under each block in the direct-belief layer. For example, if the block on the left of the direct belief layer represents what A believes about B's cognition $\left(\mathrm{M}^{\prime}(\mathrm{A}, \mathrm{B})\right)$, then the blocks in the left column of the projected belief layer represent what $A$ believes about what $B$ believes about C/A's cognition (M" $(\mathrm{A}, \mathrm{B}, \mathrm{C})$ and $\mathrm{M}$ " $(\mathrm{A}, \mathrm{B}, \mathrm{A})$, respectively). The right blocks contain what $\mathrm{A}$ believes about what $C$ believes about $B / A$ 's cognition (M" $(A, C, B)$ and $M "(A, C, A)$, respectively). The bottommost side of this layer contains A's belief of beliefs about A's own cognition. For example, in Fig. 1, the left bottom block is A's belief of B's belief about A's cognition (M" $(A, B, A)$ ). In the same way, the right bottom block is A's belief of C's belief about A's cognition (M" $(\mathrm{A}, \mathrm{C}, \mathrm{A}))$.

The blocks other than those on the bottommost side contain one's belief of a partner's belief about another partner's cognition, such as what A believes about what B believes about C's cognition (left top block). This belief structure is also placed in the third layer (i.e. not in a new layer) because it is similar to the third layer of the previous model in terms of its 'depth' of belief, which is 'projected' through someone's mind. In total, the projected belief layer has $(n-1)^{2}$ blocks, where $n$ is the size of the group. Table 2 shows the number of blocks in each layer for different group sizes.

We can also infer from the definition that if the group size becomes two, the number of blocks in the direct belief layer and the projected belief layer both become one. Therefore, the two-person version of this new model is exactly the same as the previous model. In other words, the previous model is a special case of this new model.

Similarly, the model of a four-person team is shown in Fig. 2 (individual) and Fig. 3 (team).

\section{Extensions: scalability and mental subgrouping}

As previously mentioned, one issue in expanding such a model is the belief structure when we want to apply the model to a group larger than two persons. Dividing the direct-belief layer and the projected-belief layer into smaller blocks gives the model the additional structure needed for cognition in a team larger than two. 


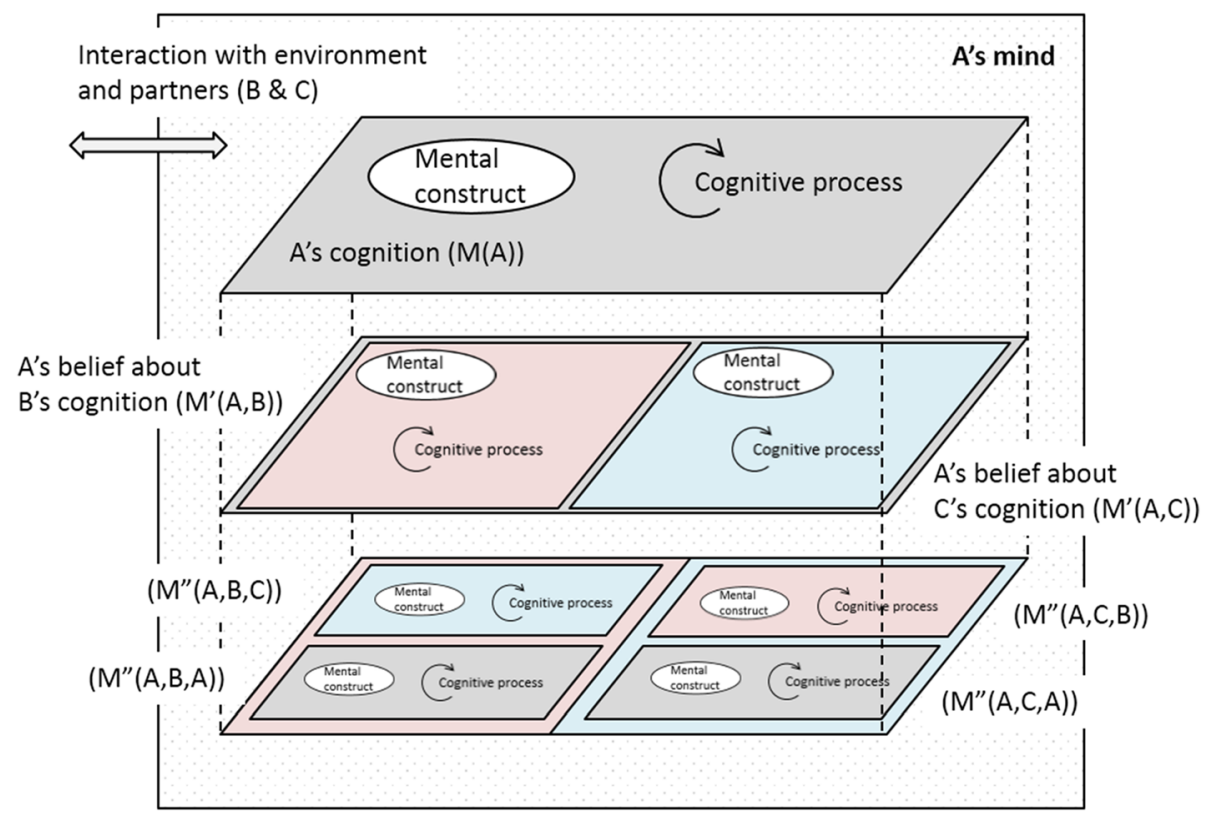

Fig. 1 Schematic of team cognition in a team of three persons

According to the previous model [10], to reach complete shared situation awareness (shared SA), each member of the team should be aware of three things: one's own SA, the partner's SA, and the partner's awareness of one's SA. Theoretically, the mental load possessed by each member increases as the number of members increases because they must pay attention to each partner's individual SA. In line with that concept, in the new model, a total of seven blocks exist in one person's mutual belief structure for a three-person group (one in the self-cognition layer, two in the direct-belief layer, and four in the projected belief layer). For a fourperson group, 13 blocks exist (one, three, and nine, respectively). As the size of the group increases, the number of blocks also increases rapidly. Empirically, humans perform mental subgrouping to handle such a situation. The proposed model represents this behaviour as block-grouping process in the direct belief layer and the projected belief layer.

By using the formalization previously mentioned, we define several mental subgrouping in the layers. The following explanation uses first-person pronouns (I, We, and the possessive form: My and Our) and third-person

Table 2 Number of blocks in different layers

\begin{tabular}{lllll}
\hline Group size & Layer 1 & Layer 2 & Layer 3 & Total \\
\hline 2 & 1 & 1 & 1 & 3 \\
3 & 1 & 2 & 4 & 7 \\
4 & 1 & 3 & 9 & 13 \\
$\mathrm{n}$ & 1 & $\mathrm{n}-1$ & $(\mathrm{n}-1)^{2}$ & $1+(\mathrm{n}-1)+(\mathrm{n}-1)^{2}$ \\
\hline
\end{tabular}

pronouns (He, She, They, His, Her, and Their) to explain the subgrouping. For consistency, the following consensus is applied hereinafter: the pronouns are used as if one or more members inside the group mention the other member(s) (including him/herself) to an outsider.

Multiple blocks are grouped into several block-groups. Note that $\mathrm{M}\left(\mathrm{S}_{\mathrm{m}}\right)$ cannot be defined because, in this model, a group is assumed not to have cognition by itself. Rather, a group has a combination of individual cognitions and their interrelationships. This concept follows the reductivism point of view mentioned previously $[17,18]$. Thus, $M^{\prime}\left(S_{m}, x\right)$ and $M^{\prime \prime}\left(S_{m}, x, y\right)$ for any $x, y$, cannot be defined.

For the direct-belief layer, the grouping is defined as follows:

- $\mathrm{M}^{\prime}\left(\mathrm{Q}_{\mathrm{i}}, \mathrm{S}_{\mathrm{m}}\right)=\mathrm{Q}_{\mathrm{i}}$ 's belief about Sm's cognition (belief about a subgroup's cognition), where $S_{m}$ is any subset of $\mathrm{G}$ containing more than one member.

As for the projected-belief layer, five possible grouping strategies exist. One of the strategies is projection through an individual, whereas the other four are projections through a subgroup. To avoid ambiguities in the personal pronouns used, in some formalizations a number inside a bracket is placed next to the pronoun to mark that each pronoun belongs to different entities (subgroups). These groupings are defined in Table 3.

From the definition of the third layer, the interpretation is that in $M^{\prime \prime}(x, y, z), x$ and $y$ cannot be the same entities, and similarly for $y$ and $z$. However, for $\mathrm{M}^{\prime \prime}\left(\mathrm{Q}_{\mathrm{i}}, S_{\mathrm{m}}, \mathrm{S}_{\mathrm{m}}\right)$, even though $\mathrm{y}$ and $\mathrm{z}$ are the same, they 


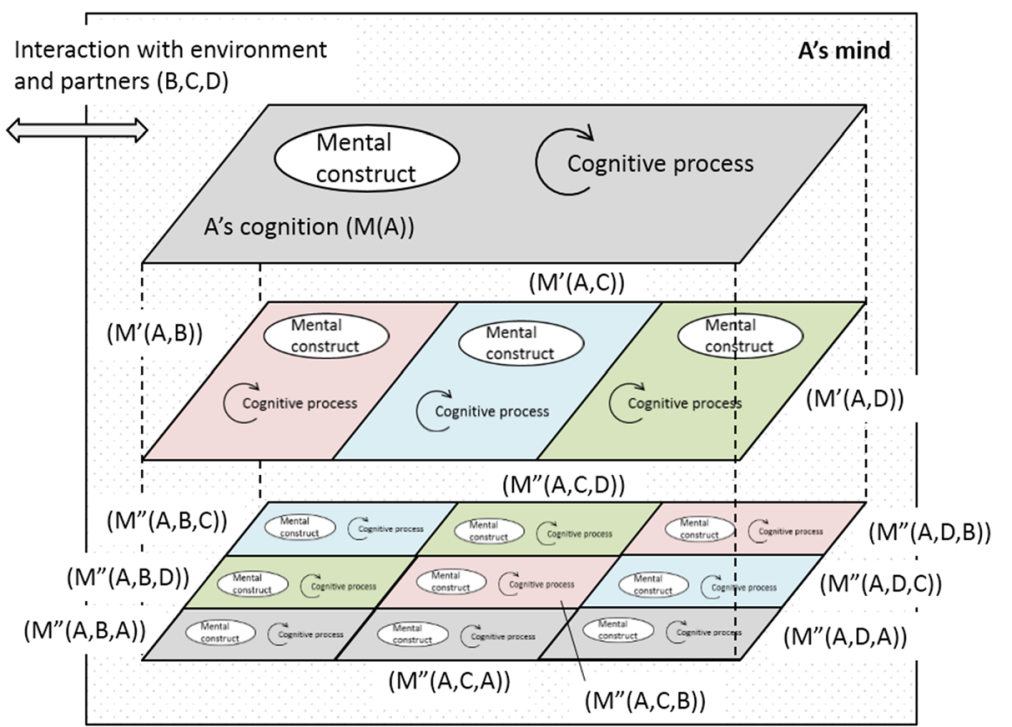

Fig. 2 Schematic of team cognition in a team of four persons (individual member: member A)

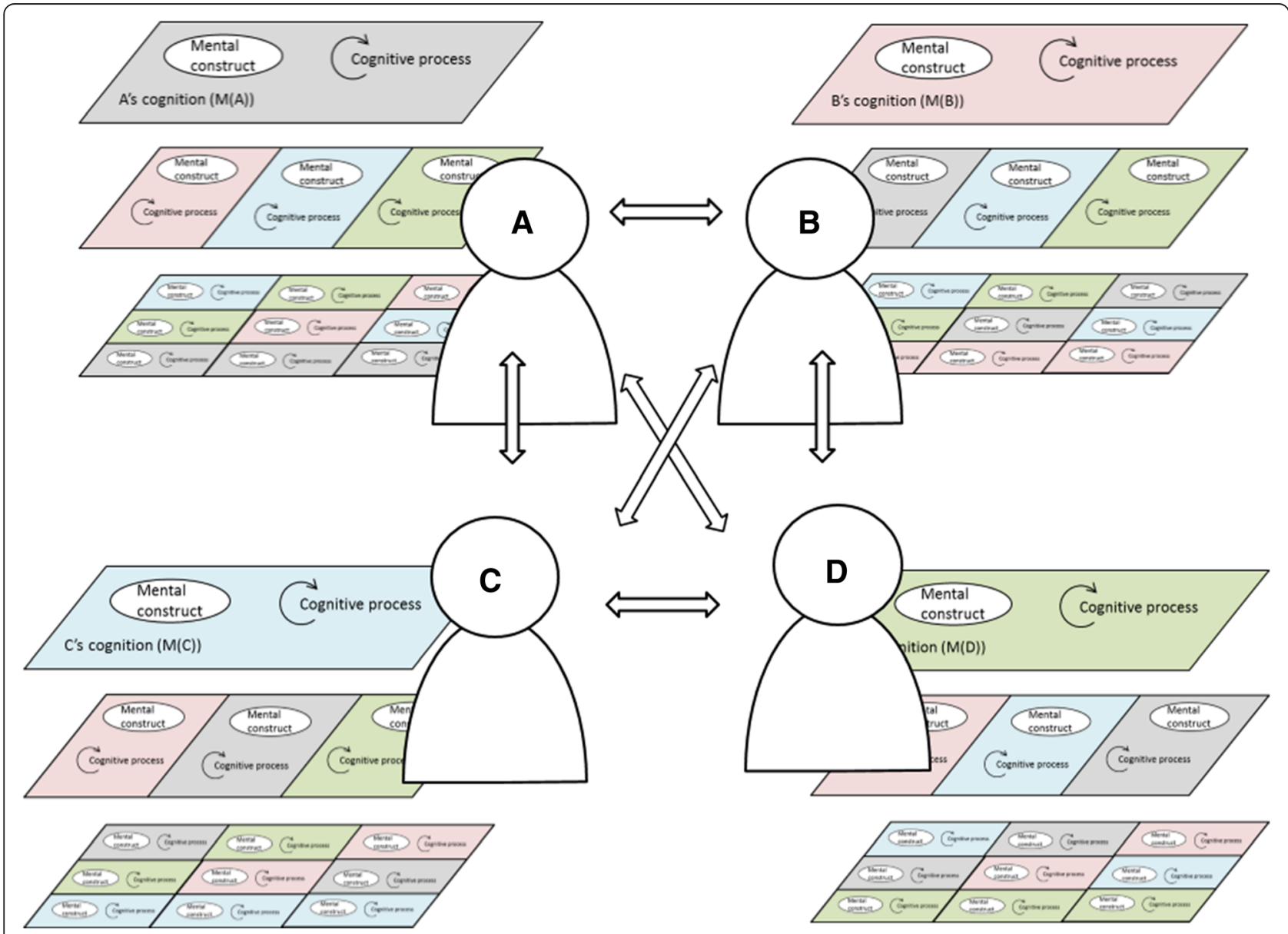

Fig. 3 Schematic of team cognition in a team of four persons (all members). Each layer-set corresponds to the belief structure of the member (i.e. member A, B, C, or D) 
Table 3 Mental subgrouping in projected belief layer

\begin{tabular}{|c|c|}
\hline Description & Example \\
\hline$M^{\prime \prime}\left(Q_{i}, Q_{j}, S_{m}\right)=Q_{i}^{\prime}$ s belief about $M^{\prime}\left(Q_{j}, S_{m}\right)$ & $\begin{array}{l}\text { - What I believe He/She believes about Our cognition } \\
\text { - What I believe He/She believes about Their cognition }\end{array}$ \\
\hline$M^{\prime \prime}\left(Q_{i}, S_{m}, Q_{j}\right)=Q_{i}{ }^{\prime}$ belief about $S_{m}$ member's belief of $Q_{j}{ }^{\prime}$ cognition, for $i \neq j$ & $\begin{array}{l}\text {-What I believe They believe about His/Her cognition } \\
\text { - What I believe We believe about His/Her cognition }\end{array}$ \\
\hline$M^{\prime \prime}\left(Q_{i}, S_{m}, Q_{i}\right)=Q_{i}^{\prime} s$ belief about $S_{m}$ member's belief of $Q_{i}^{\prime} s$ cognition & - What I believe They believe about My cognition \\
\hline$M^{\prime \prime}\left(Q_{i}, S_{m}, S_{p}\right)=Q_{i}^{\prime}$ s belief about $S_{m}$ member's belief of $S_{p}$ member's cognition, for $m \neq p$ & $\begin{array}{l}\text { - What I believe They }(1) \text { believe about Their(2) cognition } \\
\text { - What I believe We believe about Their cognition } \\
\text { - What I believe They believe about Our cognition }\end{array}$ \\
\hline$M^{\prime \prime}\left(Q_{i}, S_{m}, S_{m}\right)=Q_{i}^{\prime} s$ belief about $S_{m}$ member's belief on each other's cognition & $\begin{array}{l}\text {-What I believe We believe about each other's cognition } \\
\text { - What I believe They believe about each other's cognition }\end{array}$ \\
\hline
\end{tabular}

still do not violate the definition. In those cases, the statement is a simplification of 'what I believe about everybody's beliefs about everybody ELSE's cognition', of which each agent in the first 'everybody' (y) is different from each agent in the second 'everybody' $(\mathrm{z})$ - in other words, reciprocal (as in reciprocal vs. reflexive construction in linguistics [19]).

\section{Experiment}

The concept of mental subgrouping has yet to be deeply studied. Some studies only cover the psychological perspective of the use of pronouns (e.g. [20, 21]). Nevertheless, from the explanation of the model, mental subgrouping is very efficient in comprehending partners' cognition, primarily in a large group. Therefore, understanding the mechanism of this phenomenon is necessary.

To observe the mechanism of mental subgrouping and the mental subgrouping patterns that appear in certain situations, an experiment in a laboratory setting was conducted. Three factors were chosen for further exploration regarding the mental subgrouping pattern, such as the number of real groupings, the size of the group, and the congruence of initial decisions. The details of the experiment, including the results and data analysis, are presented in this section.

\section{Team task}

In this experiment, 21 teams of three, four, or five people (seven teams for each size) participated in a team decision-making task adapted from 'Lunar Survival' [22]. For the task, they received a fictional space adventure scenario. In the story, they were asked to rank 15 items (such as oxygen tank, pistol, water, and others) on the basis of their priority to complete the scenario. In this case, the real grouping is made using the difference in the rank. The details are explained in the next subsection.

The experiment involved 84 English speakers, both native and non-native, who represented 25 different nationalities. Most participants were graduate students of the University of Tokyo and were between 22 and
35 years of age $($ mean $=25.49, \mathrm{SD}=2.91)$. One requirement for participant selection was being able to engage in a casual discussion fluently in English.

\section{Procedure}

Each participant was given 10 minutes to answer the problem individually and create an individual initial rank (IIR) of the items without talking to the others. Next, they spent 15 minutes discussing the problem with the team to create a group rank of the items (GR). The participants were given the opportunity to engage in free discussions. At the end of the discussion, they needed to provide a single group rank that was accepted by all of the members. After completing the discussion, the members were asked about how they mentally subgrouped the members in relation to the differences in the individual ranks. In this part, the individual rank served as the real grouping. If several people have the same rank for an item, they belong in one real grouping.

For each of the 15 items, the participants were asked to create sentences using personal pronouns, such as, 'I think about something, he thinks about something else, and they about something else', 'We think about something, or other similar sentences that best represent the manner in which they were thinking during the discussion. The phrase 'about something' may represent the rank (for example, 1, 2, 14), the qualitative priority (for example, high, low), or any thought that they had when thinking about partners' ranks in the discussion (not the manner of thinking when answering the questionnaire). The purpose of this part is to determine the number of subgroups that they mentally create and its relation to the rank. Subsequently, they were asked to mention the ID to whom they were referring with the pronouns. When answering this questionnaire, they were allowed to watch a recording of their discussion to help them recall the discussion process. Examples of the answers are provided in Table 4.

In the first sentence in Table 4, participant A wrote that when he/she heard about the other members' rank, he/she 
Table 4 Grouping types in projected belief

\begin{tabular}{llll}
\hline No & Item & Sentence & Pronoun 1 \\
\hline 2 & First aid kit & We had the same answer but his is different. & we $=A B \quad$ Pronoun 2 \\
10 & Oxygen & We all had the same answer for this one. & we $=A B C$
\end{tabular}

was thinking, 'We had the same answers but his is different'. In the next column, pronoun 1 ('we') was mentioned as referring to participants $\mathrm{A}$ and $\mathrm{B}$, whereas pronoun 2 ('his') referred to participant C. In this case, two mental subgroups were created. The first group consisted of A and $\mathrm{B}$, and the second group consisted of $\mathrm{C}$. In the same manner, for the item oxygen, participant A thought, "We all had the same answer for this'. The 'we' here referred to $\mathrm{A}, \mathrm{B}$, and $\mathrm{C}-$ one mental subgroup.

In total, 1,260 sentences were collected. However, only 1,128 sentences were used for analysis because of errors (for example, the meaning of some sentences was unclear).

\section{Results and discussion}

\section{Relationship between mental subgrouping and real grouping}

To compare the number of mental subgroupings and real groupings, the analysis results of all 1,128 sentences were plotted using the number of mental subgroupings (the number of pronouns), number of real groupings (the number of different ranks), and group size. For each number of real groupings in each size, the average of the number of mental subgroups was calculated. The result is shown in Fig. 4.

As Fig. 4 indicates, when the number of real groupings was 3,4 , or 5 , the average number of mental subgroupings was close to 2 . No case exists in which a team of size 5 had 1 real grouping (the same IRR for one item in a team). This result is understandable because a team with more members will have more opinions. For teams of sizes 3 and 4 with 1 real grouping, the number of mental subgroupings was close to 1 .

In general, the average number of mental subgroupings formed for any team size is between 1 and 2. We propose the following hypothesis. When a person is working on a team, he/she tends to think of the team or the partners as one entity instead of a set of individual entities (the members) working together.

\section{Relationship between mental subgrouping and team size} The next analysis determines the relationship between the number of mental subgroupings and team size. The analysis was done by counting the number of sentences containing each number of mental subgroupings for each team size. The result is indicated in Fig. 5.

The $y$-axis represents the number of sentences containing the corresponding number of mental subgroupings. For 1 mental subgrouping, the pronoun used was 'we'. For 2 mental subgroupings, a few possibilities existed, such as 'I-they', or 'We-they'. Obviously, the maximum number of mental subgroupings in a member's mind was the same given the size of the team. For all team sizes, that condition was the least frequent.

In general, the frequency of 1 and 2 mental subgroupings was higher than that of a larger number of mental subgroupings. Mental subgroupings that result in 3 or 4 subgroups also occurred; however, their frequency declined drastically compared with fewer subgroupings. Moreover, the frequency of 5 mental subgroupings was almost zero. We propose the following hypothesis. A limit exists to the number of mental subgroupings that can be practically made, and this limit may fall between 4 and 5.

\section{Relationship between mental subgrouping and congruence of initial decisions}

The term congruence is adapted from Nail and MacDonald [23], in which they defined five different group decision situations. Congruence occurs if initial individual decisions already match the final group decision. The congruence of the initial decisions reflects the variation in an individual's reason regarding the decision towards a particular item (understanding of physical function, assumption of the story, and others). Therefore, this factor might be important in the emergence of a mental subgrouping pattern. In the context of the given scenario, each item has a different congruence level. To estimate the degree of congruence of the initial decisions, the standard deviation (SD) of IIR for each item was calculated. A higher SD indicates less congruence of the items from participants' perspective, and vice versa. These data were then compared with the average number of mental subgroupings of each item. The congruence of the items turned out to have a moderately strong positive correlation with the average number of mental subgroupings created (Spearman's $\rho=0.614$, with $n=15, \alpha=0.02$ ). Figure 6 illustrates the correlation.

The graph shows that oxygen has the lowest standard deviation and, thus, is regarded as the item with the most congruent decision. At the other extreme, a magnetic compass has a high standard deviation and, thus, its initial decision was not as congruent.

A less congruent decision towards an item will result in a more intense discussion and will generate more opinions among team members. Therefore, such a decision may 


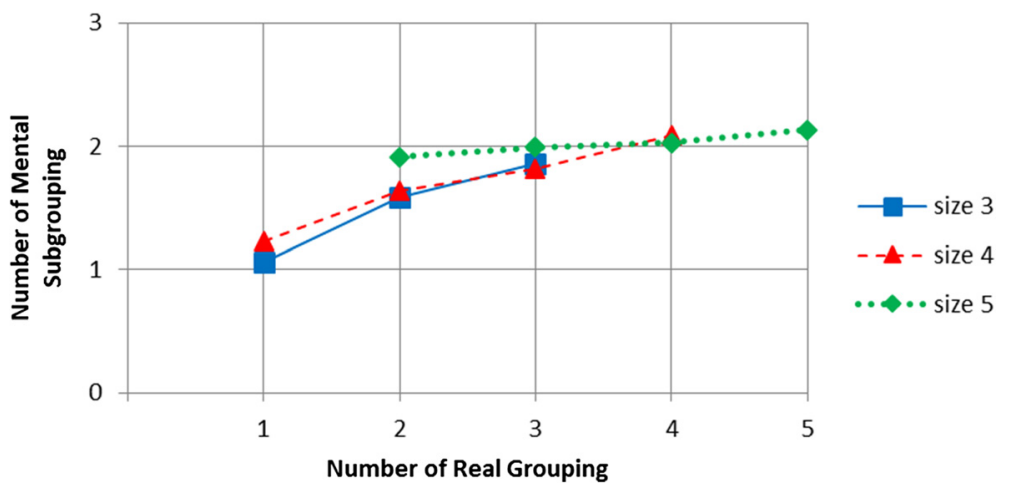

Fig. 4 Correlation between real groupings and mental subgroupings

lead to a higher number of mental subgroupings. On the basis of that finding, we propose the following hypothesis. A less congruent decision towards an item results in more mental subgroupings.

\section{Analysis and discussion \\ Reduction of cognitive load}

The experiment showed that, regardless of team size and the number of real groupings, primarily 1 or 2 mental subgroupings are actually formed. This phenomenon may be one of our mental effort to reduce the cognitive load when processing information. Human's attention is very selective $[24,25]$. When humans multitask or pay attention to more than one thing at once, their performance generally suffers. Without mental subgrouping, a team member would be required to enumerate each partner's cognition, which would probably reduce his or her performance. The role of the mental subgrouping is not to reduce the number of things to which one needs to pay attention but is, instead, to provide a simpler mental representation for the mind to process. In this way, the mind can focus on multiple things at once because these things are mentally represented in a smaller number.

A similar concept exists in social psychology called 'stereotyping'. Stereotyping refers to a generalization about the qualities or characteristics of the members of a particular group or social category [26]. Stereotyping is noted as saving time, mental resources, and the cognitive load $[27,28]$. Fiske [29] pointed out that stereotyping is a fundamental aspect of cognition and often occurs unconsciously. In the team cognition context, mental subgrouping is also a form of such a generalization. However, it is not necessarily about partners' quality or characteristic but can be about any cognition, such as perception, knowledge, memory, or intention.

\section{Inaccuracy of mental model}

Any heuristic process including such simplification of mental representation is always a trade-off between its simplicity and accuracy. In the current case, the maximum number of real groupings is five. An increase in the number of real groupings may lead to a more suboptimal decision or even an error. For example, in large-

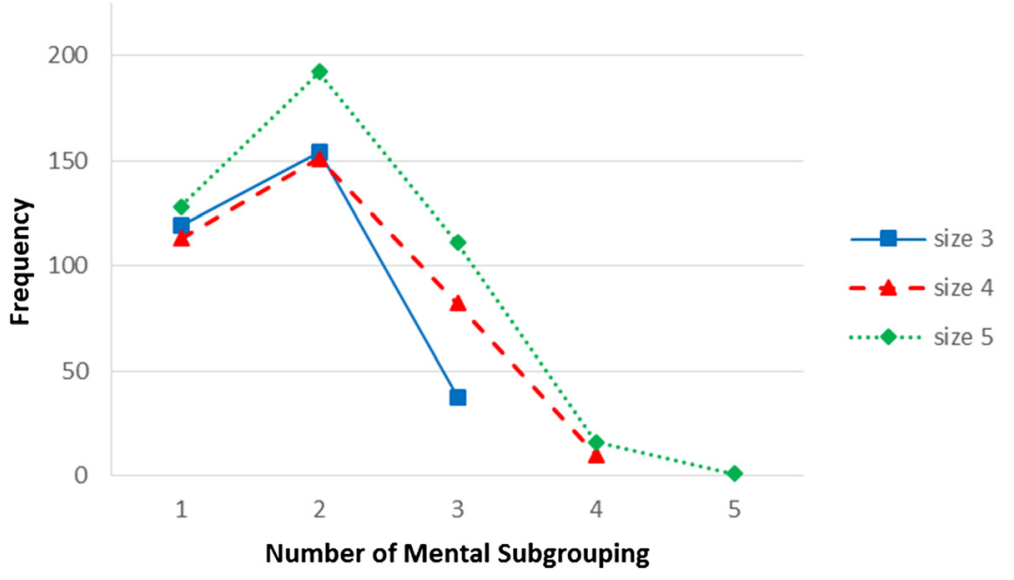

Fig. 5 Number of mental subgroupings and frequency 


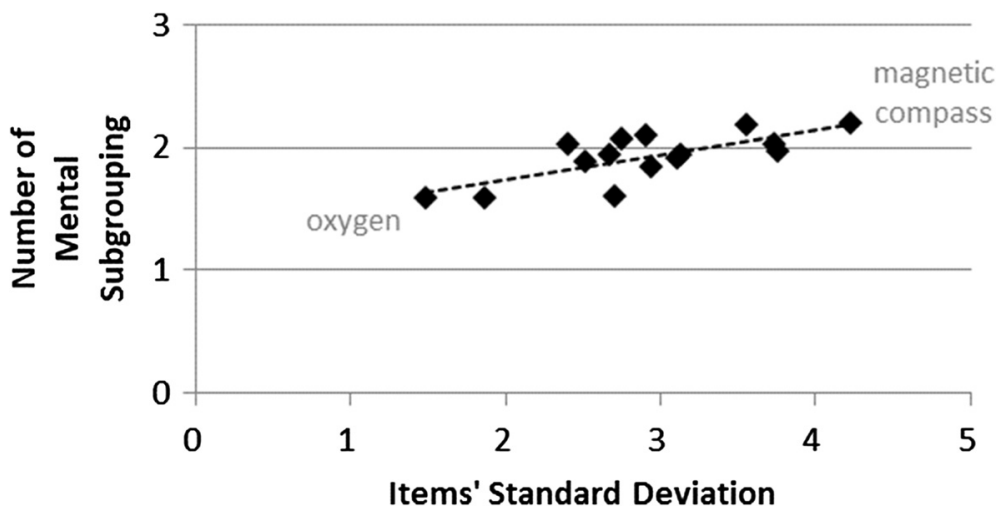

Fig. 6 Correlation between the congruence of initial decisions of the items and mental subgrouping

group decision making, a member may oversimplify the various opinions or decision alternatives given by his/her partners.

These theories lead to the conclusion that the mental subgrouping process is a mental effort to reduce the cognitive load when processing information through teamwork. Similar to other heuristic processes, mental subgrouping sacrifices the accuracy of the mental model and may lead to a suboptimal decision.

\section{Limitations and further research \\ Assumption of the reductivism point of view}

The argument by Chant and Ernst [17] about the reductivism point of view was used as the underlying assumption of the current proposed model. This perspective views a group's cognition as the combination of its individual member's cognition and a particular relationship. Given this assumption, this model is not appropriate for the analysis that assumes that a group or team is a single cognitive agent in itself.

\section{Language}

One important limitation to the current research is the use of a particular feature of a language to observe mental subgrouping. The experiment was conducted only in English, and the primary observed phenomenon is the use of English personal pronouns. Generally, this problem is common in studies related to psycholinguistics. As noted by Matlin ([25], p. 299), such studies are English-centred. Some languages, such as Japanese and Italian, are called pro-drop languages. In such languages, the use of pronouns is omitted most of the time [30], indicating that mental subgrouping may not be directly observed from such use.

\section{Variation in team conditions}

In the present study, the experiment used a decisionmaking task, and all team members have an equal position and role in the task. In the real world, in addition to the decision-making task, other types of group tasks exist, such as planning tasks, creativity tasks, and so on (see, for example, [31] for a taxonomy of the types of group tasks). Typically, team members also play different roles in a task, such as a coordinator and staffs. Different roles and different tasks may affect the mental subgrouping process.

An interpersonal relationship within an established group (as opposed to an ad hoc group such as the ones in the experiment) may also be a factor in the formation of mental subgroupings. Some members of an established group may have formed a different closeness with particular member(s), and this closeness may trigger a mental subgrouping. This factor could not be observed in the current study.

Team size is also a limitation. In the current study, only teams of size three, four, and five were assessed. To further validate the mental subgrouping behaviour in a large group, experiments in larger teams (for example, 10 or more people) may also be useful.

\section{Conclusion}

In this research, the team cognition model developed by Kanno, Furuta, and Kitahara [10] was extended to cover the explanation of team cognition for teams larger than two people. Layers and blocks were used inside layers to divide team cognition into self-cognition, direct-belief, and projected-belief.

One important aspect of the model, namely mental subgrouping, was also observed. The usage of plural personal pronouns in an experiment provides insights into the mechanism of the mental subgrouping pattern. A series of hypotheses can be developed that may be elaborated on in future studies. These hypotheses are as follows.

(1)When a human is working on a team, he/she tends to think of the team or the partners as one entity instead of a set of individual agents working together. 
(2) A limit exists to the number of mental subgroupings that can be made, and this number may be between four and five.

(3)A less congruent decisions towards an item result in more mental subgroupings.

By using the mutual belief concept and mental subgrouping, the new model can be used to model the cognition of teams larger than two persons. Further research is needed to more carefully examine how mental subgrouping is actually formed and its effect on team performance.

\section{Competing interests}

The authors declare that there is no competing interests.

\section{Authors' contributions}

DM designed the model, experiment, analysis, and drafted the manuscript. TK suggested the contextual framework of the model proposal, the structure of the article, and revision of the model mainly in formalizing the model. KF gave some critical advice to the data analysis. All authors read and approved the final manuscript

\section{Authors' information}

DM is a PhD student in the Department of Systems Innovation, The University of Tokyo. He received his Master degree in Systems Innovation from The University of Tokyo in 2014.

TK is an Associate Professor in the Department of Systems Innovation at the University Tokyo. He received his Doctorate degree in Quantum Engineering and Systems Science from the University of Tokyo in 2002. His research interests include cognitive systems engineering and sociotechnological studies for safety.

$\mathrm{KF}$ is the Director of Resilience Engineering Research Center, and a Professor in the Department of Technology Management for Innovation at The University Tokyo.

\section{Acknowledgements}

Initial version of the extended model has been presented in 2014 European Conference on Cognitive Ergonomics, Vienna, Austria. The authors would like to thank Kenta Nakamura and Adrián Agulló Valls for conducting some parts of the experiment.

\section{Author details}

'Department of Systems Innovation, Graduate School of Engineering, the University of Tokyo, 7-3-1 Hongo Bunkyo-ku, Tokyo 113-8656, Japan. ${ }^{2}$ Resilience Engineering Research Center, the University of Tokyo, 7-3-1 Hongo Bunkyo-ku, Tokyo 113-8656, Japan.

Received: 4 September 2015 Accepted: 24 January 2016

Published online: 01 February 2016

\section{References}

1. Klimoski, R, \& Mohammed, S. (1994). Team Mental Model: Construct or Metaphor? Journal of Management, 20(2), 403-437. doi:10.1177/ 014920639402000206.

2. Peltokorpi, V. (2008). Transactive Memory Systems. Review of General Psychology, 12(4), 378-394. doi:10.1037/1089-2680.12.4.378.

3. Wilson, JM, Goodman, PS, \& Cronin, MA. (2007). Group Learning. Academy of Management Review, 32(4), 1041-1059.

4. Endsley, MR, \& Robertson, M. (2000). Situation Awareness in Aircraft Maintenance Teams. International Journal of Industrial Ergonomics, 26(2), 301-325. doi:10.1016/50169-8141(99)00073-6.

5. Kellermanns, FW, Walter, J, Lechner, C, \& Floyd, SW. (2005). The Lack of Consensus about Strategic Consensus: Advancing Theory and Research. Journal of Management, 31(5), 719-737. doi:10.1177/0149206305279114.

6. Mohammed, S, Ferzandi, L, \& Hamilton, K. (2010). Metaphor No More: A 15-Year Review of the Team Mental Model Construct. Journal of Management, 36(4), 876-910. doi:10.1177/0149206309356804.
7. Endsley, MR. (1995). Toward a Theory of Situation Awareness in Dynamic Systems. Human Factors: The Journal of the Human Factors and Ergonomics Society, 37(1), 32-64. doi:10.1518/001872095779049543.

8. Rouse, WB, Cannon-Bowers, JA, \& Salas, E. (1992). The Role of Mental Models in Team Performance in Complex Systems. IEEE Transactions on Systems, Man, and Cybernetics, 22(6), 1296-1308. doi:10.1109/21.199457.

9. Cannon-Bowers, JA, Salas, E, \& Converse, S. (1993). Shared Mental Models in Expert Team Decision-making. In N. J. Castellan Jr. (Ed.), Individual and Group Decision-making: Current Issues (pp. 221-246). Hillsdale, NJ: Lawrence Erlbaum.

10. Kanno, T, Furuta, K, \& Kitahara, Y. (2013). A Model of Team Cognition based on Mutual Beliefs. Theoretical Issues in Ergonomics Science, 14(1), 38-52. doi:10.1080/1464536X.2011.573010.

11. Goleman, D. (2006). Social Intelligence: The New Science of Human Relationships. New York: Random House Publishing Group.

12. Davis, MH. (2005). A "Constituent" Approach to the Study of Perspective Taking: What Are its Fundamental Elements? In B. F. Malle \& S. D. Hodges (Eds.), Other Minds: How Humans Bridge the Divide between Self and Others (pp. 44-55). New York, US: Guilford Press.

13. Tuomela, R. (2001). Shared Belief. In N. J. Smelser \& P. B. Baltes (Eds.), International Encyclopedia of the Social \& Behavioral Sciences. Oxford: Pergamon.

14. Kanno, T, Watanabe, A, \& Furuta, K. (2009). Modeling and Simulation of Human Interaction Based on Mutual Beliefs. In Universal Access in Human-Computer Interaction. Intelligent and Ubiquitous Interaction Environments, 5th International Conference, UAHCI 2009 (pp. 674-683). Heidelberg: Springer Berlin. doi:10.1007/978-3-642-02710-9_75.

15. Soraji, Y, Furuta, K, Kanno, T, Aoyama, H, Inoue, S, Karikawa, D., et al. (2010). Cognitive Model of Team Cooperation in En-route Air Traffic Control. Cognition, Technology \& Work, 14(2), 93-105. doi:10.1007/s10111-010-0168-x.

16. Kanno, T, Furuta, K, \& Chou, T-H. (2013). A Model of the Perception Gap between Different Actors. International Journal of Quality and Service Sciences, 5(4), 382-394. doi:10.1108/IJQSS-08-2012-0009.

17. Chant, SR, \& Ernst, Z. (2007). Group Intention as Equilibria. Philosophical Studies, 133(1), 95-109.

18. Tuomela, R. (2007). The Philosophy of Sociality: The Shared Point of View. New York: Oxford University Press.

19. Maslova, E, \& Nedjalkov, VP. (2013). Reciprocal Constructions. In M. S. Dryer \& M. Haspelmath (Eds.), The World Atlas of Language Structures Online. Leipzig: Max Planck Institute for Evolutionary Anthropology. Retrieved from http://wals.info/chapter/106

20. Pennebaker, JW. (2011). The Secret Life of Pronouns: What Our Words Say About Us. New York: Bloomsbury Publishing.

21. Chung, C, \& Pennebaker, JW. (2007). The Psychological Functions of Function Words. In K. Fiedler (Ed.), Social Communication (pp. 343-360). New York: Psychology Press.

22. NASA - Langley Research Center (2006). Survival! Exploration: Then and Now. NASA \& Jamestown Education Module. Retrieved from http://www. nasa.gov/audience/foreducators/topnav/materials/listbytype/Survival_ Lesson.html.

23. Nail, PR, \& MacDonald, G. (2007). On the Development of the Social Response Context Model. In A. R. Pratkanis (Ed.), The Science of Social Influence: Advance and Future Progress (pp. 193-221). New York: Psychology Press.

24. Wickens, CD, Lee, J, Liu, YD, \& Gordon-Becker, S. (2003). Introduction to Human Factors Engineering (2nd ed.). New Jersey: Pearson Education.

25. Matlin, MW. (2012). Cognition (8th ed.). New Jersey: Wiley.

26. Forsyth, DR. (2010). Group Dynamics (6th ed.). Belmont, CA: Wadsworth, Cengage Learning.

27. Macrae, CN, Hewstone, M, \& Griffiths, RJ. (1993). Processing Load and Memory for Stereotype-based Information. European Journal of Social Psychology, 23(1), 77-87. doi:10.1002/ejsp.2420230107.

28. McGarty, C, Yzerbyt, VY, \& Spears, R. (2002). Stereotypes as Explanations: The Formation of Meaningful Beliefs about Social Groups. Cambridge: Cambridge University Press.

29. Fiske, ST. (2000). Stereotyping, Prejudice, and Discrimination at the Seam between the Centuries: Evolution, Culture, Mind, and Brain. European Journal of Social Psychology, 30, 299-322.

30. Cook, V, \& Singleton, D. (2014). Key Topics in Second Language Acquisition. New York: Multilingual Matters.

31. McGrath, JE. (1984). Groups: Interaction and Performance (1st ed.). London: Prentice-Hall, Inc. 